\title{
Does Red Lipstick Really Attract Men? An Evaluation in a Bar
}

\author{
Nicolas Guéguen ${ }^{1}$ \\ ${ }^{1}$ Business department, Université de Bretagne-Sud, Vannes, France \\ Correspondence: Nicolas Guéguen, IMABS, Université de Bretagne-Sud, rue de la loi, Vannes, 5600, France. Tel: \\ 33-297-012-663. E-mail: Nicolas.gueguen@univ-ubs.fr
}

Received: February 22, 2012

Accepted: April 9, $2012 \quad$ Published: June 1, 2012

doi:10.5539/ijps.v4n2p206

URL: http://dx.doi.org/10.5539/ijps.v4n2p206

\begin{abstract}
Previous research has demonstrated that the color red increases the attractiveness of women. It has also been found that makeup increases perceived women' attractiveness for men and was associated with perceived greater interest for the opposite sex. We hypothesized that women wearing red lipstick would be more favorably approached by men. Female confederates wearing red, pink, brown and no lipstick were seated in bars on Wednesday and Saturday nights in a popular spot on the West Atlantic coast of France. Each experimental session lasted one hour. The number of men's solicitations and the lead time of the first solicitation were used as dependent variables. Results showed that the red lipstick condition was associated with a higher number of male solicitations and a shorter lead time between the arrival of the confederates in the bar and the first courtship solicitation of a male.
\end{abstract}

Keywords: red, lips, makeup, attractiveness

\section{Introducation}

The literature examining the role of cosmetics in social perception has found that, overall, makeup is associated with a positive evaluation of a woman (Graham \& Jouhar, 1981; Cash, Dawson, Davis, Bowen, \& Galumbeck, 1989; Mulhern, Fieldman, Hussey, Lévêque, \& Pineau, 2003; Nash, Fieldman, Hussey, Lévêque, \& Pineau, 2006; Richetin, Huguet, \& Croiset, 2007). Men's positive perceptions of the physical and sexual attractiveness of women wearing cosmetics were also observed. Cox and Glick (1986) found that cosmetics were positively associated with femininity and sexiness whereas Workman and Johnson (1991) observed that women's cosmetics significantly enhanced the impression of attractiveness and femininity. Recent studies found that men's behavior was also affected by women's cosmetics. Guéguen (2008) observed that female confederates in bars were more frequently and more promptly approached by men when wearing cosmetics. Jacob, Guéguen, Boulbry, and Ardicioni (2009) found that male customers, but not female customers, in a restaurant gave more tips to waitresses wearing cosmetics.

These previous studies seem to show that women with facial makeup become more attractive for men. It could also be interesting to test if limiting the use of cosmetics to certain areas of the face exerts the same attractiveness effect. Mulhern, Fieldman, Hussey, Lévêque, and Pineau (2003) found that faces of women wearing full makeup were judged to be more attractive than the same faces without makeup, but they also found that eye makeup alone yielded higher levels of mean attractiveness ratings than foundation makeup alone. One aspect that has received little attention is lipstick and particularly the color of the lips.

Across cultures and time, it had been found that red lips are considered attractive in women (Schaffer, 2007) and it has been found that women wearing red clothes are perceived by men to be more attractive and sexually desirable (Elliot \&Niesta, 2008). Further studies showed that men seek more social contact with or display more sexual interest in women wearing red clothes (Niesta-Kayser, Elliot, \& Feltman, 2010; Guéguen, in press).

In a recent study, Stephen and McKeegan (2010) observed that participants increase lip redness contrast to enhance the femininity and attractiveness of women faces while they reduced redness contrast to enhance the masculinity of men's face. Thus, given the role of red in female attractiveness, it was hypothesized that red lipstick would be associated with an increase in male approach.

\section{Method}

\subsection{Participants}

The participants were young men judged to be approximately 20 to 28 years old. Given the fact that this 
experiment was an observational study, no demographic information was available. They were present in four bars where the experiment was carried out. The bars were situated in the center of a town of 70,000 inhabitants a seaside resort on the West Atlantic coast of France.

\subsection{Volunters}

Eight Caucasian female volunteers were recruited. The physical attractiveness of the confederates was previously evaluated by a group of 48 young men who were instructed to examine photographs of the faces of 36 women and to rate their attractiveness on a numerical scale going from 1 (low level of physical attractiveness) to 9 (high level of physical attractiveness). We selected only women with attractiveness near the middle of the scale (5-7) and precautions were taken to verify that the rate of attractiveness was not statistically different between the confederates. With these 8 confederates, 4 two-person teams were constituted according to a random selection made for each day of the experimental period.

\subsection{Procedure}

The experiment was conducted during 6 Wednesday and 6 Saturday nights between 8:30 p.m. and midnight with the consent of the owners of the fours bars. Three observational sessions of 1 hour each were conducted each night per bar: 8:30-9:30 p.m., 9:45-10:45 p.m., 11:00-12. The distribution of the confederates' team for each session and for each bar was randomized. Thus 144 observational periods were obtained: 2 days a week $\times 6$ weeks $\times 3$ sessions per day $\times 4$ bars $=144$ with $N=36$ observational periods in each experimental condition. Two male observers (20 years old) were seated in each bar where the experiment took place. A young female beautician also volunteered to make up the female confederates for the duration of the experiment. In the lipstick only condition, the beautician applied makeup only to the confederates' lips using either a red, a pink or a brown lipstick after cleaning their faces and applying a moisturizer. The same brand and its product line was used throughout the experiment. In the no makeup condition, the female confederates' lips and faces were simply cleaned and moisturizer was applied as in the other condition. The two confederates in each team were in the same lipstick condition. According to a random selection during the 12 nights in which the experiment was conducted, both of the women-confederates either wore lipstick or not when they entered the bar, and stayed with or without lipstick throughout the evening. The women were instructed to try to sit at a free table near the area where single men often stand while drinking. The two young male observers were present in the bar two minutes before the women-confederates entered. They were instructed to sit in a place where it was possible for them to observe the bar and the tables, without choosing a table near the bar. The female-confederates were instructed to sit down and begin talking to each other without showing interest in the other people present in the bar. When the women-confederates were seated, one of the observers started a chronometer and stopped it when either of the two women folded their arms. This was a code meaning that a man had made contact. A man's behavior was considered a contact if the man spoke to one of the two female confederates. Nonverbal behaviors of men, such as a fixed gaze or a smile, were disregarded because they are difficult to interpret. When a verbal contact was made by a man, one of the women-confederates was instructed to say "Hello, we are waiting for someone who will probably arrive in one or two minutes. We have a lot to talk about. Another time perhaps?" This brief statement was sufficient to stop the interaction and cause the male to leave the two confederates. The second male observer was instructed to count the number of males who approached the two women (the same code was used each time), whereas the first observer was instructed to give the "stop" signal by standing up after each 60 -minute session.

\section{Results}

The two dependent variables measured in this experiment were the time elapsed before a first verbal contact was made by a man and the moment when the women confederates sat down, and the total number of verbal contacts made by men during each one-hour session. These two sets of means are presented in Table 1 . 
Table 1. Time elapsed before the first male contact (in minutes) and number of men making contact across conditions

\begin{tabular}{|c|c|c|c|c|c|c|c|c|}
\hline \multirow{4}{*}{ Measure } & \multicolumn{8}{|c|}{ Lipstick condition } \\
\hline & \multicolumn{2}{|l|}{ Red } & \multicolumn{2}{|l|}{ Pink } & \multicolumn{2}{|c|}{ Brown } & \multicolumn{2}{|c|}{ No lipstick } \\
\hline & $\mathrm{N}=36$ & & $\mathrm{~N}=36$ & & $\mathrm{~N}=36$ & & $\mathrm{~N}=36$ & \\
\hline & $\underline{\mathrm{M}}$ & $\underline{\mathrm{SD}}$ & $\underline{\mathrm{M}}$ & $\underline{\mathrm{SD}}$ & $\underline{\mathrm{M}}$ & $\underline{\mathrm{SD}}$ & $\underline{\mathrm{M}}$ & $\underline{\mathrm{SD}}$ \\
\hline $\begin{array}{l}\text { Number of men making } \\
\text { contact by period }\end{array}$ & 2.03 & 0.70 & 1.72 & 0.70 & 1.55 & 0.69 & 1.39 & 0.69 \\
\hline $\begin{array}{l}\text { Time elapsed before the } \\
\text { first male contact }\end{array}$ & 19.78 & 9.37 & 23.35 & 11.91 & 24.83 & 14.81 & 27.03 & 13.18 \\
\hline
\end{tabular}

Note: $\mathrm{N}=36$ refers to 36 periods of observation

With the number of men's contact per hour, a 4 between groups one-way ANOVA analysis was performed. A main effect was found $\left(F(3,140)=5.09 p=.001, \eta_{\mathrm{p}}{ }^{2}=.11\right)$. Post-hoc testing revealed that the red lips condition was nearly significantly different from the pink lips condition (LSD test, $p=.06$ ) and clearly significantly different from the brown lips condition (LSD test, $p=.005$ ) and the no lipstick condition (LSD test, $p<.001$ ). Further analysis revealed that the pink lips condition was significantly different from the no lipstick control condition (LSD test, $p=.04$ ) but not different from the brown lips condition (LSD test, $p=.30$ ). Finally, no significant difference was found between the brown lips condition and the no lipstick condition (LSD test, $p$ $=.31)$

With the time elapsed before a first male contact, the same 4 between groups one-way ANOVA analysis was done and revealed no overall difference $\left(F(3,140)=2.15 p=.10, \eta_{\mathrm{p}}{ }^{2}=.04\right)$. Post-hoc testing revealed that the red lips condition was not significantly different from the pink lips condition (LSD test, $p=.23$ ) and the brown lips condition (LSD test, $p=.09$ ) but was significantly different from the no lipstick condition (LSD test, $p$ $=.02$ ). Further analysis revealed that the pink lips condition was not significantly different from the no lipstick control condition (LSD test, $p=.21$ ) and the brown lips condition (LSD test, $p=.61$ ) whereas the brown lip condition and the no lipstick condition were not significantly different (LSD test, $p=.46$ ).

\section{Discussion}

The predictions were supported by the results of this experiment. The red lipstick worn by the female-confederates was associated with higher male contact and a shorter lead time for the first contact than when no lipstick was used. These results obtained in a real social setting were congruent with the data which showed that red increases women's attractiveness for men. Niesta-Kayser, Elliot and Feltman (2010) found that men sat closer to a woman wearing a red shirt than a woman wearing a blue one, and Guéguen (in press) found that women hitchhikers wearing a red tee-shirt increased the probability of a man (but not a woman) stopping to offer a ride. Our results seem to show that a red lip color is sufficient enough to influence men's approach. These results are important given the fact that they again confirmed that makeup increases women's attractiveness (Graham \& Jouhar, 1981; Cox \& Glick, 1986; Cash, Dawson, Davis, Bowen, \& Galumbeck, 1989; Workman \& Johnson, 1991; Mulhern, Fieldman, Hussey, Lévêque, \& Pineau, 2003; Nash, Fieldman, Hussey, Lévêque, \& Pineau, 2006; Richetin, Huguet, \& Croiset, 2007; Jacob, Guéguen, Boulbry, \& Ardicioni, 2009), but they also showed that lipstick and the color of the lipstick can exert a single attractiveness effect. Indeed, in these previous studies, neither the color of the makeup nor the effect of lipstick alone were tested.

Across cultures and time, it had been found that red lips are considered attractive in women (Schaffer, 2007). In a recent study, Stephen and McKeegan (2010) observed that participants increase redness contrast to enhance femininity and the attractiveness of female faces. To explain their results, these authors stated that red lips would be associated with an indication of estrogen levels, sexual arousal and health which in turn led to increase the positive perception of the women's faces. Such positive perceptions of the women probably explain why more men approached our women confederates in this experiment. Further studies are now necessary to evaluate if a relation exists between men's behavior and the assumption that women with red lips are perceived to be more sexually aroused and healthy. It would be the next step to explore using the same methodological approach as in our experiment. 


\section{References}

Cash, T. F., Dawson, K., Davis, P., Bowen, M., \& Galumbeck, C. (1989). Effects of cosmetics use on the physical attractiveness and body image of American college women. The Journal of Social Psychology, 129, 349-355. http://dx.doi.org/10.1080/00224545.1989.9712051

Cox, C. L., \& Glick, W. H. (1986). Resume evaluation and cosmetics use: When more is not better. Sex Roles, 14, 51-58. http://dx.doi.org/10.1007/BF00287847

Elliot, A. J., \& Niesta, D. (2008). Romantic Red: Red Enhances Men's Attraction to Women. Journal of Personality and Social Psychology, 95, 1150-1164. http://dx.doi.org/10.1037/0022-3514.95.5.1150

Graham, J. A., \& Jouhar, A. J. (1981). The effects of cosmetics on person perception. International Journal of Cosmetic Science, 3, 199-210. http://dx.doi.org/10.1111/j.1467-2494.1981.tb00283.x

Guéguen, N. (2008). The effects of women's cosmetics on men's courtship behavior. North American Journal of Psychology, 10(1), 221-228.

Guéguen. N. (in press). Color and women hitchhikers' attractiveness: Gentlemen drivers prefer red. Color Research and Application.

Jacob C., Guéguen. N., Boulbry G., \& Ardicioni R. (2009). Waitresses' Facial Cosmetics and Tipping: A Field Experiment. International Journal of Hospitality Management, 29, 188-190. http://dx.doi.org/10.1016/j.ijhm.2009.04.003

Mulhern R., Fieldman G., Hussey T., Lévêque J.L., \& Pineau P. (2003). Do cosmetics enhance female Caucasian facial attractiveness. International Journal of Cosmetics Science, 25, 199-205. http://dx.doi.org/10.1046/j.1467-2494.2003.00188.x

Nash, R., Fieldman, G., Hussey, T. Lévêque, J.-L., Pineau P. (2006). Cosmetics: They influence more than Caucasian female facial attractiveness. Journal of Applied Social Psychology, 36, 493-504. http://dx.doi.org/10.1111/j.0021-9029.2006.00016.x

Niesta Kayser, D., Elliot, A. J., \& Feltman, R. (2010). Red and romantic behavior in men viewing women. European Journal of Social Psychology, 40, 901-908. http://dx.doi.org/10.1002/ejsp.757

Richetin, J., Huguet, P., \& Croizet, J. C. (2007). Le rôle des cosmétiques dans les premières impressions: Le cas $\begin{array}{lllll}\text { particulier } \mathrm{du} \text { maquillage. } & \text { Lnnée Psychologique, 107, }\end{array}$ http://dx.doi.org/10.4074/S0003503307001042

Schaffer S. (2007). Reading our lips: The history of lipstick regulation in Western seats of power. Food and Drug Law Journal, 62, 165-225.

Stephen, I. D., \& McKeegan, A. M. (2010). Lip colour affects perceived sex typicality and attractiveness of human faces. Perception, 39, 1104-1110. http://dx.doi.org/10.1068/p6730

Workman, J. E., \& Johnson, K. K. (1991). The role of cosmetics in impression formation. Clothing and Textiles Research Journal, 10, 63-67. http://dx.doi.org/10.1177/0887302X9101000109 